McDaniel, J.L.M, Moss, K. and Pease, K.G (eds) (2020) Policing and Mental Health. Abingdon: Routledge.

(Embargoed until 1 November 2019 - Funding for this chapter received from Police Mutual)

\title{
Chapter Thirteen
}

$\underline{\text { Police Misconduct, Protraction and the Mental Health of Accused Police Officers }}$

John LM McDaniel, Kate Moss, Ken G Pease and Paramjit Singh

\begin{abstract}
$\underline{\text { Abstract }}$
The chapter describes findings from a research project carried out in collaboration with one UK police force. The project was designed to examine and understand the force's welfare practices towards officers accused of misconduct and the impact of prolonged misconduct investigations on the mental health and wellbeing of police officers, specifically police officers who were subsequently exonerated. The aim was to identify new opportunities for mental health support, points of avoidable delay, demotivation and embitterment, and stressreducing possibilities throughout the misconduct process, and to produce a simple and clear evidence-based set of recommendations for improvement.
\end{abstract}

\section{Introduction}

The mental health and wellbeing of police officers has received limited academic scrutiny. Causes of police-related mental health problems (i.e. work-related pressure; injuries in the line of duty; traumatic experiences; police shootings; financial difficulties and allegations of misconduct, among others) and the impact of such problems on police conduct (i.e. poor decision-making; overzealous use of force; a reluctance to use force; rudeness; absenteeism and corruption), and on the wider police organisation, remains disjointed and sporadic (Morash et al., 2006; Slate et al., 2007; Noblet et al., 2009; Hickman et al., 2011; Schaible and Six, 2015; McCreary et al., 2017). More particularly, the manifestation of identifiable mental health problems, such as anxiety, acute stress disorder, depression and post-traumatic stress disorder (PTSD), and their subsequent treatment, remains under-researched and poorly understood in a policing context (Brewer and Wilson, 1995; Meffert et al., 2008; Linden et al., 2008; Gershon et al., 2009; Blagden, 2012; Miller, 2015; Bullock and Garland, 2019). Although the body of academic research at the nexus of policing and mental health is 
growing, this area of policy and practice, as well as the broader field of 'police psychology' (Kitaeff, 2011), remains in a relatively embryonic state.

The chapter addresses largely virgin territory by examining the impact of prolonged misconduct investigations on the mental health and wellbeing of police officers within one police force in England and Wales. Drawing upon empirical research conducted with the cooperation of one of the largest police forces in the jurisdiction, the chapter identifies new opportunities for mental health support, points of avoidable delay, demotivation and embitterment, and stress-reducing possibilities throughout the misconduct process. It argues that protracted misconduct investigations can perversely affect police officer welfare, police decision-making, use of force and police culture and attitudes, often without remedy. Neither police investigators nor supervisors appear to be taking adequate responsibility for the mental health of accused police officers. This applies to both internal Professional Standards Departments (PSDs) and the external Independent Police Complaints Commission (IPCC), replaced by the Independent Office for Police Conduct (IOPC) in 2018. Although national guidance holds that the purpose of the misconduct process is to maintain public confidence in the police service, 'uphold high standards in policing and deter misconduct and protect the public', and specifically not to 'punish police officers' (College of Policing, 2017, p. 6), it would appear that, in reality, accused police officers are being punished, both directly and indirectly, in a myriad of ways.

\section{Methodology}

The research relied primarily upon in-depth interviews with 11 police officers who had been subjected to protracted misconduct investigations, cleared and returned to work. The aim was to examine their experiences from a mental health and well-being perspective. The police force provided access to some case files relating to the proceedings against the officers for the purposes of documentary and textual analysis. However, it was unable to provide all of the documents for each case; some cases had a large number of associated documents, whereas others had very few. The research was carried out with the support of the police force, and its Professional Standards Department, who were clearly keen to make improvements where appropriate.

The fact that 11 out of more than 6,000 serving constables in the police service contacted the researchers to be interviewed, after blanket email invites had been sent out by both the police 
service and the Police Federation, indicated at the outset that protracted misconduct investigations (which are followed by the exoneration of officers) are not a common occurrence. However, neither the police service nor the Independent Office for Police Conduct (IOPC) publish comprehensive overviews of the number of cases which result in exoneration in the form of 'not proven' or 'no further action' outcomes. The IOPC's (2019) 'Police Complaints Information Bulletins', for example, only outline more generally the number of allegations and complaints received, the nature of the allegations and investigation, and the number of cases finalised and appealed within a period, amongst other limited data sets. Case outcomes were generally only uploaded ad hoc onto the police service website, generally for a six month period before being removed, with the result that relevant statistics were not available for direct comparison and analysis.

Nevertheless, it is not unusual for evidence-based policing research to develop hypotheses drawn from a relatively small number of interviewees as a starting point for further investigation (see Bayliss and Quinton, 2013; Fyfe, Stevenson and Woolnough, 2015). Participant-oriented methods, such as Glaser and Strauss's 'Grounded Theory', emphasise the importance of users of processes, and enable us to move from specific observations to broader generalisations in order to render a conceptual understanding of them (Glaser and Strauss, 1967; Glaser, 1992). In addition, it is likely that a number of exonerated officers chose not to come forward for interview for a variety of reasons, not least a reluctance to speak out about their present employer. The officers who did come forward, did so on the basis that their interviews would be anonymised.

In the absence of an established definition of a 'protracted' misconduct investigation, the researchers considered a case to be prolonged or protracted if it lasted more than 18 months from the date the complaint was recorded. By no means do we recommend that 18 months should be used as a standard for a 'protracted' investigation. On average, it took a lot less than 18 months for misconduct allegations to be finalised nationally in the period between April and December 2018 (IOPC, 2019). Moreover, in the context of criminal investigations, sections 4 and 5 of the Prosecution of Offences Regulations 1987 hold that the period between the accused's first appearance in court and the commencement of trial should generally take no longer than seven months for an indictable offence, particularly where they are held on remand. It is even less for summary offences. In 2014, the average time taken between an offence being committed and the case being resolved in a Magistrates 
Court was more likely to be closer to six months, while the average time for a Crown Court case was 12 months in England and Wales (Open Justice, 2015). The 12 month average for Crown Court cases reportedly consisted of an average of 20 weeks between the date the offence occurred and the charging of the defendant, three weeks between the charge and the first hearing and 29 weeks between the first hearing and the judgement or outcome (ibid). On this basis, it appears that a hypothetical standard for 'protraction' could lie substantially under the 18 month mark.

The cases in the sample ranged from durations of 18 months to a little over 4 years, occurring between 2012 and 2017. They consisted of a spectrum of allegations, from the planting of drugs to the forced use of an individual's pillowcase as an improvised 'spit hood'. It covered cases which emanated from members of the public who had submitted complaints following a stop and check; and conduct matters emanating from officers complaining about a colleague or from supervisors reporting a subordinate and vice versa. There was a mix of misconduct and gross misconduct allegations. The former, once substantiated, result in a misconduct meeting which is generally chaired by a Superintendent (or a senior officer two ranks above the accused). The latter, gross misconduct allegations, are judged to be so serious that, if proven, they should result in the officer's dismissal. These are adjudicated at a misconduct hearing consisting of a three-person panel which contains a legally qualified chair, a senior police officer at least two ranks above the officer (usually a chief superintendent or above) and an independent member.

The sample also included incidents which were investigated solely by the police force's Professional Standards Department (a local investigation), and investigated independently by the Independent Police Complaints Commission (IPCC). The officers who faced the misconduct process included police constables, sergeants and an inspector. We did not differentiate or analyse the sample on the basis of rank, age, length of service, gender or ethnicity, nor did we attempt to evaluate the probity of the outcomes (i.e. whether there should have been a finding of 'proven' rather than 'not proven'). Our focus centred on the systems designed to identify mental health problems and triggers, and the mechanisms established to prevent, support and address them.

$\underline{\text { Recognising the impact of misconduct investigations on the mental health of police officers }}$ 
The research indicated that the police service and the external complaints body did not fully appreciate the mental health problems affecting accused police officers. The scale and longevity of mental health problems encountered in the study were significant, and shocking. One officer reported that 'throughout the whole of this process it affected me massively......stress, mentally and physically ...for 4.5 years I probably did not sleep right at all ...' (Interviewee 3). Other interviewees, particularly those who faced the risk of dismissal (gross misconduct), reported that they had suffered serious anxiety over the prospect of losing their house, their car, their relationship and their children, if they found themselves dismissed without notice and without an income. More than one police officer said that they were unable to function as loving partners and parents because of the shame and anger that they felt. They described using anti-depressants; a loss of self-confidence; losing weight and suicidal thoughts. There was frequent use of the terms 'meltdown', 'breakdown' and 'suicide' (Interviewees 3, 8 and 9). It appeared that their emotions could be further amplified in the event of relatively normal occurrences such as celebrating Christmas, going on holidays, getting married, moving house, a death in the family, or the birth of a child. These emotional events in their personal lives, where there was an expectation of happiness or a need to grieve, appeared to be common 'trigger points' for the development of mental health problems, or the amplification of them.

'When we found out that my partner was pregnant with my first child I almost had a breakdown.....I didn't know what to do..... it's not that I didn't want children.....I've always wanted children.....it's not that I didn't want to be with my partner because I wanted to be with my partner ......but sheer panic just went through me.....something was out of control and it's the closest to my life I thought I was going to have a breakdown really. ......I had suicidal thoughts through this...... at that point in time I was at my lowest .....I was worried I was going to lose my job ... how was I going to provide for her and my baby...... it filled [me] with absolute dread' (Interviewee 3)

'We were supposed to get married, we never did.....we did not want to get married under a cloud. We wanted to move house but we did not know what sort of money I was going to be on, so we didn't move house. Home life was put on hold' (Interviewee 1) 
A combination of these feelings and issues frequently affected the officer's ability to continue working while a misconduct investigation was ongoing. Although the suspension of accused officers was commonplace up to five years ago (one of the officers in the sample was suspended for almost three years - Case No. 2), since 2014 it has become the police service's policy to relocate officers to another unit, where possible, once it is assessed that an allegation requires a formal investigation (usually within two weeks of the complaint). The test that is usually applied is such that if the conduct, if known, would impact on public confidence in the police and public perception of the police, the officer should be taken out of the evidential chain, particularly where there is potential for the officer to interfere with evidence or have direct supervision over officers who are witnesses against them.

However, once relocated, the officers in the sample reported feeling increasingly distracted and 'worthless' both because of the ongoing investigation and the reduced or changed workload they encountered (Interviewee 1).

'first day back and I have now been kicked out my office, I can't even go into the ... office ... so it's best if you don't see anybody there, it's best if you don't speak to anybody in relation to the case......so my team have now lost their Sergeant, I now can't speak to them ... So I had to sit at this desk with nothing to do' (Interviewee 11)

'The hardest thing was having something meaningful to do I suppose while all this was going on. In some ways it would have been kinder to suspend me and let me be free......it felt like almost being in open prison......that's how it felt. You are under investigation, you have to come in, clock in everyday, stay for your hours and clock out ...' (Interviewee 1)

A stigma associated with being under investigation emerged as a particular theme throughout the interviews. One interviewee divulged that it ' ...felt like I was on police bail for the whole time' (Interviewee 3). Another described it as 'a red beacon over you going "I am under investigation" (Interviewee 3b). These feelings did not appear to emanate due to a peculiar sense of internal paranoia or psychosis but were largely reactions to and amplified by externally generated rumours and innuendo and a lack of support structures. One officer revealed that 'there were lots of rumours.....I was getting lots of texts and people/friends speaking to me saying... everyone's saying you are going down the steps....started 
questioning myself then...' (Interviewee 1). As a result, several officers felt that they could not continue working and took sick leave, which typically lasted between a month and four months. Officers reported that once you take sick leave 'it is difficult to go back' because of the emotion and stigma associated with perceived wrongdoing (Interviewee 3b; Interviewee $6)$.

\section{Recognising the long-term impact on police officer performance and wellbeing}

The emotional and mental health problems unleashed by the misconduct process had far reaching consequences. Exonerated officers reported that they had 'changed ... completely as a person' (Interviewee 3), struggled to regain their productivity, no longer saw themselves as the same kind of police officer once they returned to work, and no longer believed that the police service treated its officers fairly. In terms of productivity, officers reported being unable to concentrate and a general sense of disillusionment. One officer confessed that: '...[I] just don't know if it's what I want to do with my life - be a police officer anymore...... f feel very badly treated. No offender would be on bail for 4.5 years and waiting for answers' (Interviewee 3). He recounted 'numerous periods where I have been at work and just think "I am not concentrating, I can't be bothered with this.....tell me why am I doing this" (ibid). It was not unusual for officers to consider leaving the police force as a result, particularly for a police force elsewhere in the country.

An overall loss of trust in the police service itself was palpable, particularly due to a perceived lack of fairness and the absence of organisational learning throughout the misconduct process. No interviewee reported any organisational learning following their case. In fact, in numerous internal documents, the space at the end of the investigator's decision under the heading 'Organisational Learning' remained blank. One Sergeant offered the following view on organisational learning:

'... the force did a press statement saying that a lot of the learning and recommendations had already been implemented.....that is a load of nonsense.....there has been no changes.....there is no training.....there is nothing what so ever. That is a lie' (Interviewee 3b).

The experience of being under investigation not only affected levels of trust in the organisation but it had a direct effect on how officers exercised their powers in future and 
how they managed subordinate officers. The experience of being under investigation manifested into a real reluctance to use physical force (i.e. to restrain someone) upon the officer's return to work, almost turning the perceived (and expected) 'fight or flight' response of police officers on its head. One interviewee divulged that:

'I struggle to now deal with violence, getting hands on people, because I've got no confidence that it won't get dealt with straight away ...even though I've been found not guilty or no case to answer and have body cam I have still got no trust in the system ...' (Interviewee 8)

Other officers reported similar feelings, such as: 'if I saw something now I would shy away from it. I wouldn't take hold of people...' (Interviewee 7); and 'if I go home this week and have not arrested anybody I ain't got a problem - no complaints' (Interviewee 2).

Even once they had been cleared or exonerated, several officers referred to the 'Sword of Damocles' continuing to hang over them (popularised in a parable by the Roman philosopher Cicero, symbolising an inability to enjoy life and fortune if one is constantly in fear for their life). One officer observed that:

'all the time you got the sword hanging over your head because that is what it felt like. It was difficult because you then got sent to jobs and thinking hang on if I do this job how I normally do it and I get a result ... am I still going to end up going to a hearing for this because I have done it properly' (Interviewee 5)

Somewhat surprising in light of the above, none of the interviewees showed any tendency towards or expectation of loyalty from their colleagues (Waddington, 1998; Reiner, 2010). By and large, they appreciated that 'being complained about as a police officer is the norm' and that 'if a police officer goes out there and hits someone or lies about something or steals something ... all of us in that job will want them to be disciplined......we don't want them in the job either if they behave like that' (Interviewee 6). Their bitterness appeared to lay squarely with the misconduct process and the investigative mechanisms directly associated with it. 
The attitudes of officers towards the misconduct system tended to shape their working relationship with colleagues and their approach to management, particularly in the context of police transparency and accountability. One officer remarked that "when you think people don't trust PSD officers ..... “oh PSD coming in today don't say anything"..... kind of get where that is coming from' (Interviewee 4). Another commented that:

'I have always been a massive advocate really of saying to my staff "do the right thing and ... if you are doing the right thing the job will defend you"..... now my view has totally changed because I found myself at a misconduct meeting for simply charging someone with the criminal offence that they had committed ... it's changed my views completely really ... cause I used to think innocent people would not end up disciplined, but when it nearly happened to me, I suppose it left a really bad taste in my mouth' (Interviewee 6)

These reactions and residual feelings were amplified in many cases by the fact that the allegations remained on the officer's file and continued to hang over the officers' heads even after they had been cleared. For example, the 'Centurion' database is used by the vast majority of police forces in the UK to record, manage and process police complaints and police professional standards data; and can provide an audit trail of tasks and results. This misconduct database, when searched, continued to link officers' names to allegations such as 'racist complaint' even though they had been cleared. The existence of the Centurion record, allied to the suspicion and stigma which the officers had been subjected to during the investigation, meant that officers struggled to shed the cloak of suspicion once they returned to work. One officer commented that 'you don't want to ... just have [the record] laying on your file...... someone is going to look at that and think "no smoke without fire".....so it is a matter of principle ...' (Interviewee 6). Others took issue with the negative connotations associated with the findings of 'no further action' (NFA) and 'not proven' remaining on their file. It was not unusual to hear officers say "not proven intimates to me they believe I have done it, they just couldn't prove it' (Interviewee $8 \mathrm{~b}$ ). The lingering stigma and record of the allegation not only acted as a personal burden for the officers concerned, but it could hinder them from getting subsequent character references from senior officers who 'refused on the basis that ... [they] don't really want to be dragged into this' (Interviewee 8b). 
It is clear that a fulsome and supportive misconduct process should not be resulting in such perverse and detrimental outcomes. The accusatory, dysfunctional and stigmatic misconduct system appears to be causing people to become chronically embittered and to pull back from their work in order to avoid complaints or because of simple disillusionment with the job and the wider organisation. What started out as a source of stress linked directly to (or caused by) the police organisation (an 'organisational stressor'), appeared to manifest into a stressor which directly impacted upon the front-line duties that officers performed (an 'operational stressor') (see Bullock and Garland, Chapter 12). The views that officers held at the culmination of the misconduct process were never properly addressed or even challenged by the wider organisation. The fact that serving officers used words such as 'witch hunt', 'evil', 'conspiracy theory' and 'horrific' to describe the misconduct process (Interviewees 1, 2 and 6), even after they had been cleared, suggests that there was something deeply problematic about their experiences. These views not only affected the officer's sense of self and identity as part of a policing organisation but it shaped how they advised other officers and subordinates and how they carried out the policing task.

\section{Finding the locus of responsibility for mental health support}

The police service was clearly aware that officers were suffering from emotional and mental health problems during the course of the misconduct process. For example, more than two years after being notified of an allegation, one accused officer received a letter from PSD which contained the words 'I do not underestimate the stress and anxiety that the delay with the case has and is causing ...' (Case No. 5). In a separate case, the investigator recorded in the Investigation Log that the police officer under investigation attended their office 'in tears', with her Federation Representative (IO Log, Case No. 1). However, there was no evidence that the police service reacted to or addressed their clear mental health needs.

Although there are a variety of ways in which the mental health needs of police officers could be met, there did not appear to be any direct and systematic mental health processes embedded within the police complaints process. The only real mention of any mental health construct was the force's Welfare Officer (mentioned in Cases 2, 3, 4 and 7). The Welfare Officer is normally a more senior officer assigned by the senior leadership team to act as an initial contact, triage point and referral mechanism for officers and staff, and to provide a follow up review of the treatment provided by internal or external counsellors and other Approved Mental Health Professionals (AMHPs). In theory, the role includes the collation 
and analysis of data to identify developing psychological health trends and the implementation of effective interventions, which can include providing advice and guidance to line managers and accused police offices about welfare support and return-to-work plans, which can help to mitigate against specific causes of work-related stress and mental health problems. In practice, the senior leadership teams in the police service typically appointed a Welfare Officer directly from the accused officer's team, and only if the case was deemed appropriate or seriousness enough. For instance, if an officer admitted the allegation(s) at the outset, a Welfare Officer was not usually appointed. In reality, the Welfare Officer appointed was more often than not the accused officer's line manager, who generally received no additional training or terms of reference to carry out the role. There was little evidence to suggest that Welfare Officers engaged with accused subordinates in a meaningful way, outside of their basic line management duties. There was nothing more than passing reference to the Welfare Officer in official police correspondence, and they appeared to be largely invisible to the police officers under investigation. Referring to their Welfare Officer, one interviewee stated that '.......for the first 7 months I had nobody...... Thinking oh god what the hell is going on here' (Interviewee 2).

In the absence of professional support, the majority of officers under investigation were particularly scathing of the quality and level of support provided by senior managers. Observations included: 'my old Inspector didn't speak to me, my commanders never emailed me or anything......no one asked how are you doing' (Interviewee 1); '.....after it happened no senior member of staff phoned me up and spoke to me' (Interviewee 3); and 'our Inspector wasn't supportive at all ... all he was interested in was protecting himself' (Interviewee 3). One officer compared it to being 'ostracized for 2 years' (Interviewee 11).

There were some fleeting examples of good leadership. One officer reported that 'while we were off, I had a phone call every week from my Sergeant' (Interviewee 5), but such occurrences were rare, and they did not serve as a panacea for all ills. In a separate case, an officer observed that 'a Sergeant ... would support me and the new Inspector would support me......but when I am sitting here saying "support" it consisted of a chat if I was to go into the office and chat about it myself' (Interviewee 3). In most cases, the Welfare Officer role extended to little more than the line manager (acting as the Welfare Officer) putting return-towork plans into place, which typically included referrals to occupational health and a discussion around flexible working, once officers had already been exonerated. 
In the absence of more systematic support, and facing pervasive rumour and innuendo, it appeared to be far more likely for officers to encounter the unsolicited support of colleagues. One officer reported that: 'one of the things I will take away ... is the amount of character evidential statements that my colleagues provided for me and some of the things they said in their statements......that means a lot to me ... My friends were my support' (Interviewee 3). Unfortunately, for this officer, and common amongst others, was the fact that they only recognised the extent of such support after the hearing (and exoneration) had taken place.

In contrast, the Police Federation of England and Wales (PFEW) was lauded by the participants for the quality of service provided. The Police Federation is a statutory staff association dating back to the Police Act 1919, which primarily serves to represent police officers and staff, below the rank of Superintendent, in disputes with police services and government. The interviewees praised their assigned Police Federation Representatives (Fed Reps) for their support, knowledge, experience and professionalism during interviews with investigators (Fed Reps routinely attend interviews to assist accused police officers and staff); for arranging meetings with solicitors and barristers; and for their regular communication and constant reassurance that everything was being done to help. One interviewee said of the Federation:

'... the Federation, maybe they overprotect some people who shouldn't be protected to that degree, you've got lazy staff, bad sickness records ... I am sure you have that everywhere ... but then it was like "halleluiah" they were there for me......it was really daunting ... 14 days to do this, 21 days to do this and how can I do all that in this timescale because my job's still going on here at the same time......but [the Fed Rep] took a lot of that away from me and he said "you give me everything"...... so that lifted a weight off my shoulders...' (Interviewee 6)

In the absence of adequate mental health safeguards and processes within the police service, the Police Federation appeared to provide the accused police officers with significant support. Fed Reps clearly tried to draw upon their own knowledge and experiences to reassure the police officer and manage their expectations throughout. One of the themes which emerged from the study was that the police service recognised that the Federation provided a valuable service to police officers, so left it to provide all kinds of administrative and mental health 
support to officers during the investigative process. It was not clear from the study, and there appeared to be opposing views within the police service, whether this role had implicitly shifted from the police service to the Police Federation over time, or whether the police service had ever consciously accepted or embraced this role in the first instance.

It is submitted that the Police Federation appears to have been left, somewhat reluctantly and informally, with the responsibility for providing mental health support during misconduct investigations, while line managers/ welfare officers have been given the hollow task of belatedly fixing the damage (once it has already been done) upon the officer's return to work. The ad hoc nature of welfare support throughout the investigative process indicated that the police service did not have systematic processes in place to provide effective mental health support to officers under investigation. The police service appears to have, consciously or unconsciously, shirked primary responsibility for police officer mental health support throughout the misconduct process.

It is important to note that, while lauded by the interviewees, the research project did not involve an analysis of Police Federation policies and practices. The quality of their processes, the forms of advice provided to accused police officers, and questions about whether and to what extent the Police Federation help or hinder police services in particular contexts (for example, whether an accused police officer is encouraged to provide a full and unadulterated statement at the outset, without waiting for the investigator's interview), remain largely unexamined from an academic perspective.

The remainder of the chapter will identify ways in which the police service can potentially provide better mental health and wellbeing support to accused police officers, possibly addressing some of the above issues. It will identify some of the underlying processes which appear to be contributing to the anxieties and mental health problems inflicting accused police officers.

\section{A problem of communication during the investigative process}

There do not appear to be any regulations which govern the frequency and extent to which an Investigating Officer (IO), whether working internally for a PSD or externally for the IOPC, should make contact with an accused police officer. The police service under review encouraged its investigators to provide accused police officers with updates on the $28^{\text {th }}$ day of 
every month. Indeed, best practice identified within the sample involved monthly contact between investigators and accused officers. At the outset of one investigation, the IO, a Detective Constable, emailed the accused to say that 'you will be receiving your Regulation Notices shortly. Throughout this investigation, I will contact you on a monthly basis. If you have any queries, feel free to call me...' (Progress Report, Case No. 8). Periodic emails from the same IO (more than ten emails in eight months) included the following informative update:

'With reference to the complaint made against you by .... The matter has now been reviewed by CPS and the decision they have made is not to take any further action in respect of a criminal prosecution. A misconduct file will now be prepared and sent to the Senior Leadership Team. They will make a decision as to whether there will be any case to answer in relation to misconduct issues. I will update you further as soon as I am in receipt of their decision. If you have any further questions, please contact me on [phone number removed]...' (Progress Report, Case No. 8)

However, such best practice was far from evident in all cases. A lack of communication was a constant issue raised by the interviewees. Examples ranged from almost monthly email contact to minimal contact outside of the sending of formal regulation notices (which typically outline that formal allegations and investigative decisions have been made). Observations from interviewees included the following: 'it just felt like ground hog day every day, coming in.....no email about the case' (Interviewee 1); and '[the] investigator is supposed to give me an update every month and it never happened' (Interviewee 3). Other officers didn't even know who to contact, with one officer sending a letter to PSD one year after a complaint had been made, stating that:

'myself and [another officer] are currently subject of a complaint .... I appreciate you may not be the correct person to contact however, myself and my colleague have no idea who we can go to ... I am currently receiving counselling due to this incident, but mainly due to the amount of time this is taking and the lack of updates I have received' (Progress Report, Case No. 1).

One officer was even hopeful that the lack of communication meant that '...maybe it's just gone away.....maybe they have dropped it or done whatever because you never get any 
correspondence from PSD......nobody keeps you updated with what's happening...' (Interviewee 6). The officer sent an unsolicited email to PSD requesting an update about the investigation but did not receive a response for six months. Upon receiving a reply (after the six month wait), the IO reported that the officer was 'livid' once she was told that the allegation was now being dealt with via a misconduct meeting and not management action, a much lesser outcome. It was jarring to note that in some cases, the complainant clearly received far more updates than the accused police officer (as evidenced in the Progress Reports). The Progress Reports on the Centurion system typically contained all important dates, ranging from the date the complaint was received to the dates of all correspondences with both the officer and the complainant.

In terms of communication, a constant theme which emerged from the research was the perception that the accused police officer was somehow expected to be more resilient than the normal citizen. Drawing comparisons to how the police are expected to treat suspects and victims, one officer commented that:

'in fairness PSD are shocking at their communication with staff ... we have a Victims Code for how we have to communicate with the public.....you know reply within 28 days ......but none of that applies ... So when we have a complaint about us you can wait months and months and months ... I think [the PSD] think it's the police and so it doesn't matter.....it does not count...I don't think they think about how it affects people....... and I probably didn't until I was in it...' (Interviewee 6)

In another case, an officer was even chastised for seeking updates: '... [The Fed Rep] came around to my house ... basically telling me not to contact PSD directly .....he has had a bollocking off them from me chasing them.....I should not be chasing them......[I should] talk to them when they interview me...' (Interviewee 1).

Once they were contacted, a frequent and connected problem was the quality of information provided to the accused officer. It was not uncommon for interviewees to report that they either didn't receive monthly communications or 'were getting ones that said 'I haven't done much since the last time I spoke to you" (Interviewee 3b). For example, more than three years after one complaint was recorded, PSD sent a message to the accused police officer stating that 'I can confirm that I have contacted Legal Services who have advised me that 
they will progress counsels advice for you as a priority'. Almost three months later, the same PSD officer added 'Dear PC ... Just a note to update you that we are still awaiting the full advice from Legal Services/counsel before I can progress any further at this stage ... as I am sure you appreciate that this is a complex case' (Case No. 7). Little more than a copy-andpaste template, the apathetic nature of such a response was not lost on the accused police officers, with one remarking that '.....a blanket phrase every time we asked for an update [was]... "it's with legal service" (Interviewee 3). This was clearly a source of immense frustration for particular officers:

'I couldn't understand why it took something like 12 months....because you can't keep people on bail that long ... somebody is sitting in their ivory tower whose got to make a decision.....either we have got it or we haven't got it.....but let's be clear about why we haven't made a decision yet......' (Interviewee $8 \mathrm{~b}$ )

In order to alleviate some of the stress and anxiety of constantly waiting for replies and notifications, the officer's Fed Rep routinely offered to act as a proxy by corresponding with the PSD or IOPC on their behalf. Only one officer in the sample availed of this service, explaining his rationale as follows: 'I got one or two more emails and then I think I am a bit pissed off with it ... I said to the Fed Rep make sure everything goes through you because I don't want to hear from them' (Interviewee 4). However, the majority of police officers wanted to receive correspondence directly, and clearly craved more communication, information and explanation of the process so that they could 'understand what's coming next' (Interviewee 6). Unfortunately, the frequency and quality of communication appeared to depend heavily on the preferences and whims of the Investigating Officer.

\section{A problem of confirmation bias}

A significant problem identified by the interviewees and evident within the police service's records, was a tendency towards 'confirmation bias'. Confirmation bias, in a policing context, typically occurs when an investigator searches for and interprets new evidence and information in a way that confirms his or her pre-existing beliefs or theories (Rossmo, 2009; Roach and Pease, 2013; Monckton-Smith et al., 2013). Interviewees identified confirmation bias, and the anxieties that such perceptions caused, in some of the following ways: 
'I felt like they were determined to prove that I'd lied.....not determined to find out what had actually happened but there seemed to be an emphasis on making me change my mind' (Interviewee 1).

'the IPCC take everything on face value which is wrong and don't seem to do the digging in the background and even when it's pointed out to them its potentially wrong they don't hand it back and say "okay we can end it now"' (Interviewee 5)

'eventually we get this paperwork through about the case ... you read through it and you get more and more angry because there was no actual evidence that we done anything wrong......just opinions of officers' (Interviewee 1)

A common theme throughout the case files was that, rather than stressing that an allegation was far from proven, the investigator's thinking and decision-making in many cases appeared to be highly accusatory from the outset, verging almost on a presumption of guilt. The language in numerous reports frequently slipped between describing allegation and suggesting fact. For example, a description of an allegation using objective language, or best practice, could involve a statement as follows: 'It is alleged that [the officer] assaulted a member of the public during a search'. However, it was not unusual for statements to drop the 'it is alleged' phrase in favour of more suggestive alternatives. For example, in one case, the IO determined that 'The officers have only considered prosecuting the complainant after becoming aware that he had made a complaint. They have not been truthful in their dealings in this matter ... [they] have lied in interview' (Case No. 8). Such language would appear to directly conflict with Schedule 3 of the Police Reform Act 2002, s. 23, which holds that the IO is not expected to predict what the outcome of any Misconduct Panel or Meeting might be, but rather to assess whether the alleged conduct is capable of amounting to Gross Misconduct or Misconduct (if proven), or neither. The legal test to be applied at the subsequent panel or meeting is such that, on the balance of probabilities, it is more likely than not that an allegation is proven.

One clear example of confirmation bias permeating an entire case is as follows. The case concerned an allegation that an officer had used a police vehicle to ram a civilian vehicle. The accused officer claimed that it was the civilian vehicle that had hit the police car. The case took 19 months to reach a conclusion. At the outset, the initial 'Assessment Form', 
which is typically a two to three page document completed once a complaint is received, held that the 'CCTV enquiries corroborate [the complainant's] account and undermine the officer's version of events'. The statement was repeated almost verbatim at the start of the investigator's log. The language used by the investigating officer, a Detective Chief Inspector, appeared to have been adopted directly from the initial Assessment Form, conveying the clear belief that the CCTV showed the police vehicle moving and turning into the path of the complainant's car causing the collision. The accused police officer continued to argue that his car was stationary and that he did not cause the collision. Once the case was referred to the Crown Prosecution Service (CPS) for charge, the prosecutor subsequently found that while the CCTV did show the event, it was of poor quality, in that the top of the screen was cut off. The CPS concluded that the CCTV offered only a limited view of events, as the two vehicles were at the top of the screen and partially off-camera. It appeared to the prosecutor that both vehicles were moving, which was in direct contrast to the account of both sides, and, most importantly, that it was open to the defence to suggest that the image at the top of the screen was distorted and that the police vehicle did not 'veer'. Moreover, it was open to interpretation as to whether the police vehicle was actually in motion at all. As a result, the CPS advised that no further action be taken, unless additional evidence came to light. The accused police officer had also watched the footage prior to his initial interview and had already reached the same conclusion:

'So they showed it...... [my Fed Rep] turn's to me and says "I am really sorry but that CCTV doesn't shows anything.......in fact it matches your statement"......the solicitor was beaming and got a big smile on his face......we still had to have the interview ...' (Interviewee).

However, once the accused officer went to the interview, the investigating officer continued to interpret the CCTV evidence in a way which appeared to confirm his pre-existing beliefs:

'so we went into interview and ... we watched it ... [he] started saying "is there anything you would like to change in your account now" and I said "no" ... the investigator got quite aggressive in his tone ... "no you have lied look at the CCTV again" ... we must have watched it about five times ... I was reading through my statement as it was going through and I was like that is what I have said happened ... He did get quite aggressive to the point where even my solicitor had to step in and say 
you have asked him the same question five times and you have got the same answer, could we move on or are we just going to keep trying to bully...' (Interviewee ).

Despite receiving the recommendation of the CPS and recording the officer's observations, the investigating officer, who appeared convinced of the complainant's version of events, recommended that the case progress to a misconduct hearing. The IO stated in their decision, known as a Regulation 19 Decision, that:

'I have reviewed the summary of evidence in the Regulation 18 report [which is typically compiled by subordinate detectives, outlining the allegations, circumstances, evidence and investigative actions in the case, and placed before the Appropriate Authority for consideration], together with all evidence secured during the investigation. My determinations as Appropriate Authority are as follows ... the only discernible movement is of the police vehicle towards [the complainant] ... The evidence suggests that the officers have a case to answer for providing false and misleading accounts and they have not been sincere and truthful ... If proven, this is so serious to warrant dismissal'.

The IO determined that the officer had a case to answer for a breach of the standards of 'honesty and integrity' for lying; 'duties and responsibilities' for his driving, and 'discreditable conduct' for bringing the good name of the force into disrepute. Unsurprisingly, at the misconduct hearing, over a year after the issuance of the Regulation 19 Decision, the misconduct panel reached the same finding as the CPS, determining that none of the infractions could be proven. It concluded that 'The only possible evidence in the case against the officers which could be said to be relevant was the CCTV evidence which all parties agreed was open to interpretation'.

Throughout the investigation, the IO did not appear to engage in an objective and factual search for the truth, largely discarding the statements of the accused police officer and the CPS advice. Both the accused police officer and the CPS had established different narratives which did not fit with the investigator's preconceived beliefs. Quite remarkably, this was far from an isolated incident. In Cases 4 and 7, both of which involved allegations of police officers repeatedly punching detainees, the IO appeared to disregard other narratives, particularly that of the police officer involved, causing misconduct proceedings to continue 
on the basis of their individual and preconceived beliefs rather than the strength of the available evidence. In both cases of alleged excessive use of force, the panel found that the allegations were 'not proven', indicating that the use of force appeared reasonable in the circumstances (both detainees were resisting and were not wearing handcuffs).

In another particularly stark case, an Inspector alleged that one of his officers had taken his designated police car without permission for his own personal use, thereby taking advantage when the Inspector was not there and putting members of the team in a difficult position. The accused officer claimed that he had taken the vehicle for policing purposes, leaving it at another police station overnight, and that all members of the team had standing permission to take the vehicle for policing purposes when the inspector was not there. Numerous members of the team supported the officer's assertion that the inspector had given clear and verbal 'standing authority' for the car to be parked overnight at other police stations. The officer had also stated in his interview that the Inspector 'hated' him.

Nevertheless, and in spite of some compelling evidence that the car had been used appropriately and for a policing purpose, the IO determined that

'...there is strong indication that [the officer] has behaved in a manner which would justify the bringing of disciplinary proceedings ... it is vital and ethically correct for [the officer] to appear before a misconduct meeting. His appearance will promote and maintain public confidence in the police service ... and to promote and maintain proper professional standards and conduct for members of the profession ... I am of the opinion that a properly directed panel would determine that a breach of the standards of professional behaviour had occurred amounting to misconduct' (Investigator's Log, Case No. 11)

Unsurprisingly, the panel at the misconduct hearing found that the allegation was not proven, far from it. It found that:

'there was a culture of taking cars to a nearest police station ... On this basis it seems likely ... [that] you [the accused officer] assumed an implied permission to do the same on the [date in question] ... it seems to me on the balance of probability you felt you were acting within your policing ... role ... I am content therefore that on [the 
date in question] you believed you were acting in a policing purpose in using the vehicle'.

In fact, the panel was quite scathing about the quality of the IO's decision-making. Noting a delay of almost two years in finalising the matter, it concluded that 'much of what is alleged could have been dealt with at a lower level, with a conversation with your line manager, clearer communications and suitable advice ...'.

Numerous accused officers criticised comparable crusading approaches, highlighting the problem of confirmation bias and the tendency of the IO to disregard the views of police officers, expert witnesses and CPS recommendations. As one officer noted, when conducting an investigation, the investigator should pursue all reasonable lines of inquiry, whether these point towards or away from the suspect, adding that ' ... you can't direct an investigation just in the direction you want...' (Interviewee 11). Another officer observed frankly that 'once CPS have said there is no evidence it's a strong indication that there is no evidence ... it's an early opportunity for them to say "actually we haven't got a lot of evidence"” (Interviewee 1).

The perception that a misconduct investigation could continue regardless was a major source of anxiety, frustration and anger for the accused police officers, and was arguably a root cause of a myriad of problems. It was not unusual for interviewees to convey the sense that 'there was nobody there to have that fresh set of eyes' (Interviewee 11), describing the frustration (and despair) as follows:

'.....basically it took until the Chair in November to look at it [2.5 years after the initial allegation] ......obviously he had looked at it ... and he thought "oh that's rubbish - drop it" ....it's a joke -2.5 years to question my integrity and then to just drop it like that. That really, really hurt me... no-one [at PSD] looked at that and thought this is a bit weak....not just weak but ridiculous and no one even questioned' (Interviewee 3)

'... the superintendent that was set to chair the panel [of a misconduct meeting] ... she was like what the hell is all this about ... that's when PSD must have looked at it.....somebody fresh must have looked at it and thought I don't know what we have done here.... It was heard in my absence and NFA'd [No Further Action] with 
nobody giving any evidence ... the panel wrote a report back to PSD saying it should never have come to this (Interviewee 6)

The overzealous approach of the investigating officer was not limited to the PSD. Case No. 5 concerned a police officer's alleged failure to undertake a thorough risk assessment after a pillow case was placed over an arrested person's head to prevent them from spitting, remaining in situ while the individual was transported by van to a nearby custody suite. The case was investigated by the IPCC and took almost two and a half years to be resolved. Throughout the case, the IPCC's investigating officer appeared to believe adamantly that the officer's risk assessments at the time concentrated on the potential risk to him and his colleagues, rather than an assessment of the risks posed to the individual. The IO concluded that the officer had sufficient time to risk assess the situation he was confronted with, and that there was a sufficient number of police officers in attendance to move and transport the detainee without use of an improvised spit hood. The IO concluded that the use of the pillowcase was 'wrong ... remaining on [the individual] for far longer than was necessary or safe ...' (Case No. 5, IPCC Report p. 43). However, no advice was offered as to how the officers could have removed the hood without the risk of being spat at instantaneously. It was far from clear how the IO expected the police officers to move the individual while mitigating the risk of spitting - in other words, how to prevent the individual from turning their head. The officers had never received organisational guidance or training on such processes (which was well known to the IO).

Subsequently, provided with the same set of facts and evidence, the misconduct panel argued that, contrary to the view of the IO, it could not be said that such a risk assessment could only have led to the conclusion that the pillowcase should have been removed. It concluded that, even once the detainee had been transported to a police station, upon opening the rear door of the vehicle (a cage van) the individual would have been in a confined space above the police officer, making removal of the pillowcase a potentially risky step. Unlike the IO, the panel accepted the account given by the officer in his oral evidence, which was tested in crossexamination, stating that 'it is plain from what we have heard that the officers took into account the individual's welfare in their risk assessment' (Regulation 36 Notice).

The weight attached to the IO's opinion throughout the investigative process appeared to be particularly problematic. The IO, in many cases, appeared to attach significant weight to his 
or her narrow perception, particularly in the presence of other explanations. Such narrow decision-making served to detach the IO's decision-making process from the appropriate evidential standard required. In misconduct cases, the burden of proof rests with police force (the Appropriate Authority) to prove that misconduct was more likely to have taken place or not; it does not rest on the officer to prove otherwise. The CPS appeared to be very aware of this standard, hence its comprehensive rejection of weak cases, but the IO appeared to lack the basic awareness of legal and evidential standards in particular cases. One officer described the investigative process as a 'a catalogue of errors really....' (Interviewee 2).

It is submitted that the IO's crusading or overzealous approach could be influenced by a number of somewhat perverse factors. The mention of phrases such as 'the public would expect';'[the accused officer's] appearance will promote and maintain public confidence in the police service' and 'it is vital and ethically correct for [the officer] to appear before a misconduct meeting' suggest that there is an implicit desire to institute misconduct meetings and hearings in the interest of promoting and maintaining public confidence in the police service, perhaps over and above the pursuit of truth and justice. Just because an allegation appears to be so serious that it should merit resolution in public, doesn't mean that it should be. Yet the superficial appearance of accountability, rather than the substance of it, seemed to be prized by some IOs. Some interviewees conveyed a suspicion that, while 'there are a lot of good workers' within PSD (Interviewee 3b), some investigators were zealously pursuing convictions not in the interests of truth and justice but to gain plaudits and to secure promotion. One interviewee proffered the view that some officers applied to join PSD:

\footnotetext{
'because you get your Detective qualification.......if you tried a couple of times to get it through various methods and departments and not really got anywhere it's a cheap and easy way to become a Detective ... and promotion ... a lot of bobbies - weak candidates for promotion tend to try and get someone disciplined for something' (Interviewee 1)
}

The IPCC was, in turn, accused of pursuing an allegation for populist political reasons in the case involving the use of the improvised spit hood. At the time, the police force had no policies in place relating to the use of spit hoods, nor did it have any guidance or procedures to deal with persons spitting. One of the accused officers involved felt that the IPCC was pursuing the alleged breach primarily with a view to changing force policy: 
'We started to feel that because [the police force] had no policy what so ever for spit hood or guards or whatever they wanted to call them, we were being used as guinea pigs.......the IPCC knew that the police had no regulations on the use of spit guards ... they needed a tick in the box result' (Interviewee 5)

In light of these possibilities, it is recommended that the opinions of IOs should be rigorously tested for two elements: a) the potential presence of confirmation bias; and b) to ensure the required evidential tests are being met. Not only was there no evidence to suggest that such reviews were taking place, but there appeared to be an almost complete lack of appropriate checks and balances regulating the IO's decision-making processes, allowing prejudicial language and suggestions of guilt to take hold unchallenged.

\section{A problem of definition}

Another major cause of anxiety, which appeared to affect all of the officers in the sample, was a lack of clarity around the nature and number of alleged breaches that they were accused of. This frequently emanated from the mandatory 'regulation notices' which they received. A Regulation 15/16 Notice (pertaining to Regulation 15 Police [Conduct] Regulations 2012 and Regulation 16 Police [Complaints and Misconduct] Regulations 2012), known colloquially as a 'Six', is typically a two to four page long written notification sent from the investigating body to the accused officer. The notice usually starts with the name of the complainant, the name and contact details of the IO, the case reference, and begins with a prescription similar to the following: 'This is to notify you at the earliest possible stage that an allegation has been made that your individual conduct may have breached the Standards of Professional Behaviour and that there will be an investigation into the circumstances'. The officer is then cautioned that: 'Whilst you do not have to say anything it may harm your case if you do not mention when interviewed, or when providing any information ... something which you later rely on in any misconduct proceedings or special case hearing or any appeal proceedings'. The details of the conduct that it is alleged may have breached the Standards of Professional Behaviour is subsequently outlined and the officer is informed that the conduct described, if proven or admitted, would amount to a breach of the standards of professional behaviour, culminating in a finding of either misconduct or gross misconduct. 
Upon reading the notice, the police officer is left in little doubt as to the incident it pertains to. For example, one notice described how:

'it is suspected that between [specific dates], an officer has taken a ... police motor vehicle without lawful consent and used the vehicle for personal use. Furthermore, during a fact finding exercise into the movements of that vehicle, the officer failed to disclose that he had used the vehicle. You have been identified as the officer subject of this investigation' (Case No. 11)

In a similar fashion to the criminal process, each allegation or distinct part of a complaint must be listed separately by an investigator. The task of separating an allegation into its constituent components is often complex. In many cases, a single complaint can be distilled into numerous allegations against a single officer. For example, one complaint concerning an officer who had planted drugs during a property search led to allegations about the use of unauthorised intelligence sources and evidence to secure the search warrant, and the improper completion of database entries, amongst several other allegations (Case No. 2). To a similar extent, in the aforementioned case of the improvised spit hood (for which the complainant was later found guilty of assault by spitting), when answering bail for an alleged assault of two ladies, the complainant made allegations about: the arresting officers (for assault); the officers who transported him to the police station (for failing to carry out an appropriate risk assessment); the custody sergeant (for failing to maintain a comprehensive custody record which recorded the individuals complaint in relation to his improper treatment); and the officers who were last at the scene (for failing to properly lock his front door once everybody had left). The complaint concerned 11 officers in total (the arresting officer, response officer, two duty sergeants, two CID officers, two Taser trained officers, two cage van officers and a custody sergeant).

We found some notices which contained no more than three sentences about the alleged conduct, and some of more than three paragraphs. In terms of timeliness, the written notice should be served as soon as practicable, unless to do so would prejudice the investigation or any other investigation (including a criminal one). Any decision not to inform the police officer must be recorded and kept under regular review in order to avoid unreasonable delay (the research did not uncover any such cases). Although initial notices were supposed to be sent as soon as practicable, timescales varied considerably across the sample. In a number of 
cases, the IO spent weeks reviewing evidence, taking statements and waiting to interview the complainant before sending the initial notice. We spoke to one officer who had received their first notice within three days of a complaint being made and others who received their initial notices between four weeks and four months after the initial complaint.

Police officers may also receive multiple notices in a piecemeal fashion since investigators have a duty to record and disclose additional alleged breaches as they arise. The majority of officers in the sample received subsequent notices containing new allegations up to 12 months after the investigation had commenced. As one officer recalled:

'I was served my 2nd lot of Sixes [Regulation 15/ 16 Notices] by the IPCC......so because of what I had said at interview they had gone away and done enquiries, checked phone records, got more statements from the people I had talked about in my interview ... etc, etc... because of the information they obtained they served me with my 2nd lot of Sixes...' (Interviewee 3)

Sending notices in a piecemeal and periodic fashion was a significant cause of anxiety for officers in the sample, particularly in light of the lack of support and communication they experienced. The delay in issuing a notice in one case was so great that a subsequent hearing panel stated that "we are conscious that the delay in issuing the regulation 16 notice may have affected the officers' memories, and we are willing to make allowances for that...' (Regulation 36 Notice, Case No. 5).

Although investigators could arguably do little about the sending of periodic notices due to the multi-faceted nature of many allegations and investigations, the opaque nature of the notices was apparently a greater cause of anxiety and stress for the interviewees. In most cases, the investigator conveyed the admirable quality of being able to distil the complaint into individual allegations with a reasonable degree of precision, but failed to tie specific allegations to specific breaches of the Standards of Professional Behaviour. For example, an allegation that an individual was assaulted for no good cause by a police officer and arrested for no good reason was explained to the accused officer as follows:

'[the complainant] was assaulted for no good cause by police officers - There is a case to answer in relation to this allegation. I assess that this matter amounts to misconduct 
in respect of the Standards of Professional Behaviour. I consider that formal misconduct proceedings are appropriate and recommend that the matter should be dealt with by way of a misconduct meeting' (Case No. 10)

No mention was made of a specific infraction or breach of the Standards of Professional Behaviour. Rather than specifying a particular infraction, it was not unusual for notices to outline the allegation followed by a generic statement such as: 'the allegation is subject to investigation under conduct legislation and, if substantiated, would be contrary to the Standards of Professional Behaviour' or 'the allegation is subject to investigation under criminal and conduct legislation' (Case No. 11).

When infractions were mentioned, there was invariably more than one of them listed. For example, an allegation of the planting of evidence was linked to 'Honesty and Integrity' and 'Discreditable Conduct', whereas the development of unauthorised intelligence from a covert human intelligence source (CHIS) was determined to amount to issues of 'Honesty and Integrity' and 'Duties and Responsibilities'. It was often unclear to the accused police officer which standard applied to which particular act. This was particularly pronounced in cases which listed three or four standards without tying them to particular acts. Moreover, where the police officer was accused of gross misconduct, it was unclear whether all of the allegations together amounted to gross misconduct or whether if an individual allegation was proven (and other allegations were not), it would amount to a lesser case of misconduct. The Professional Standards Department appeared to struggle in many cases to pinpoint and clarify the exact breaches alleged, and the lack of clarity was a clear source of confusion and anxiety for the officer's concerned.

Furthermore, in some cases, accused officers were only notified of which disciplinary infractions they were facing once their solicitor received the disclosure documents a few short months before the disciplinary hearing. PSD wrote to one accused police officer more than three years after the initial complaint stating that 'as soon as we have received the advice from counsel we as a team will prepare ... a bundle of the documents to assist you and your legal team with preparing your case and this will provide you with the knowledge of the breaches that you will be facing' (Progress Report, Case No. 7). Another police officer received an email from PSD over 12 months after the complaint to the effect that: 
'we are waiting for Legal Services to complete the Reg 21 notice [which is the formal notice of referral to a misconduct hearing], the notice explains the breaches of the Standards of Professional Behaviour and gives you an opportunity to present representations why the breaches have not occurred and why it is not gross misconduct. Legal Services like all of us, have a high workload hence the delay in producing the Reg 21 notice' (Progress Report, Case No. 1).

It is remarkable that police officers only received clarification of the infractions they faced years after the complaint had been made and only a matter of weeks before the hearing. As one officer recalled:

'they can only give us ....access to all the papers.....something like six weeks before the hearing.....so that was the first time I actually got specifically what they were questioning me about...... potentially what I was going to have to go answer questions for ... [it] was the first time in nearly 4 years since I had actually been told "this is what they are saying you did or didn't do"' (Interviewee 3)

Other interviewees reported seeing, as part of the disclosure process, a report of all of the complaints that had been made during their career, some of which they 'did not even know about' (Interviewee 4). One officer discussed sitting down 'until 4am/5am every night going through every single sentence and sheet' of a large bundle of disclosure documents three weeks before the hearing in order to understand the case against them (Interviewee 2). Another officer reported that he had to take sick leave just to prepare for his disciplinary hearing:

'I think we got all the information ... then a few days later we were seeing this solicitor, then we were seeing the barrister...... so I had to prepare.......so I said to me gaffer "look I have tried to come into work to do this preparation but there is no office conducive to it ...let me work from home"......... and he wouldn't let me. So......I could not cope anymore ..... and so went off work ...so the whole time I was preparing for the hearing I was off work' (Interviewee 3b)

It is submitted that, while IOs could not escape the number of allegations that needed to be dealt with in any one case, dealing with allegations in a piecemeal and obfuscated manner 
was severely problematic for police officers. The lack of detail around the specific infraction(s) and the fashion in which they were notified undoubtedly affected police officers' understanding of the process, undermined their ability to defend against allegations and helped to substantiate the perception that investigating officers would not rest until they found 'something'. Investigators may prefer to keep their options, and those available to the misconduct meeting or hearing, as open and wide as possible, but this should not extend to a lack of basic clarity or natural justice for the accused police officer. Accused officers, once provided with one or more notices that they are under investigation, should arguably receive specific and understandable information about the allegation(s) that they face, tied clearly and distinctly to the ten standards of professional behaviour, allied to appropriate mental health and administrative support.

\section{A problem of criminality}

To complicate matters further, investigators could also identify possible criminal charges for referral to the CPS, which they did quite readily. For example, in the case involving the alleged ramming of a civilian's vehicle, the IO recommended the criminal offences of 'careless driving', 'dangerous driving' and 'perverting the course of justice'. In fact, it was not unusual for allegations of dishonesty to result in referrals for 'perverting the course of justice' and 'misconduct in a public office' with a view to securing a criminal conviction rather than simple dismissal.

In one distinct case, an allegation that three officers had stopped a pizza delivery driver for no good reason, racially abused him and abused their authority by demanding that he call them 'Sir' was referred for charges of perverting the course of justice and misconduct in public office. The latter charge related to the allegation that after the complaint was made, in order to neutralise it, the officers colluded to fabricate a reason for the vehicle stop. Upon referring the case to the CPS, it decided not to bring any charges. The CPS was critical of the IO for referring potential criminal charges without sufficient evidence or understanding of the evidential tests which needed to be met. The CPS reminded the IO that to bring a charge for perverting the course of justice, the officers had to intend to pervert rather than just be reckless as to the potential consequences, and that it was often difficult to tell whether the errors in their accounts were deliberate and intentional lies rather than a mistake. Where the case relied only on the word of the complainant and the accused police officer, it would be difficult to prove a deliberate lie beyond a reasonable doubt. Indeed, in such cases, even the 
misconduct panel would struggle to reach any outcome other than 'not proven' on the balance of probabilities, as the panel explained:

'... [the complainant] describes the officers as being rude and abusive and making fun of him during the interaction. The officers all deny there was any inappropriate language or behaviour on their part ... In this matter there is very limited corroborative information to support either the accounts of the officers or [the complainant] ... all these accounts contain some flaws, inaccuracies and concerns. It is unsatisfactory, but none the less the case, that we are unable to determine with any certainty whether to accept [the complainant's] or the officers' account - both are possible. Consequently we do not find that the allegations against the officers are proven as on the balance of probabilities as we cannot say that [the complainant's] account is more likely to be true (Regulation 36 Notice, Case No. 8)'.

Although apparently popular with misconduct investigators, the bringing of criminal charges proved fruitless in these cases while, at the same time, being detrimental to the officers concerned. More particularly, the practice perpetuated the view that the investigating officers were doing everything within their power to find 'something' to charge and were 'always going to find something...' (Interviewee 3), typically in a way that would do most damage to the officer. This was reflected by numerous interviewees as follows:

'... they actually hit [the police officer] with everything including criminal misuse of public office and that's what they tend to do ... lets go for the higher and then we can reduce it' (Interviewee 3b)

'they look at you as a person and try and find what is the worst thing that they can possibly do to you ... [in contrast] the way we deal with criminals is the path of least resistance' (Interviewee 1)

'at no point was this about what had happened.....this was about what they could try and prove...... a lot of PSD investigations have come across that way.......it's not what the officer has done or what's the true account of what's gone on here, it's what's the worst thing that we can do this officer for and once they've got you in their sights they go at you...' (Interviewee 1) 
'......they went on a massive witch hunt......served me with another eight or ten offences out the blue...... I was on assault, running illegal informants, carrying out illegal searches, perjury x 3 , diverting the course of justice $\times 2$, and misconduct in a public office....' (Interviewee 2)

'I wasn't surprised that they were investigating me.......I was perhaps surprised that a number of accusations were made on the fact that it was criminal...' (Interviewee 3)

'...the criminal aspect of the case was dropped..... which was obviously a bit of relief cause that meant that I could still lose my job, but I wasn't going to be going to Prison... a police officer's worst nightmare to think that they could potentially go to prison for what they have done' (Interviewee 3)

Rather than enhancing confidence in the system, the practice of CPS referral gave accused officers the impression that every mistake or infraction, whether concerning matters of honesty or the use of force, would result in a criminal charge, which brought with it the inherent possibility of dismissal, a potential prison sentence and a criminal record. Although such outcomes were an immediate cause of significant anxiety and a trigger for other mental health issues (which were not addressed by the police organisation from the point the accused officers were notified), bringing criminal charges seemed to be a first resort for many IOs, even where disciplinary infractions appeared to be more suitable. As one officer opined:

'when it's perceived that you made a mistake in the police more often than not it's criminal and that's the major problem...... and it seems to go straight to criminal and gross misconduct and not like "hang on someone's made an honest error here"" (Interviewee 8).

\section{A problem of protraction}

The specific causes for protraction were varied and, surprisingly, the biggest delays did not appear to emanate from the evidence-gathering stage of the investigation itself. Investigative actions identified within the sample were usually prompt. Processes such as: (re)interviewing the complainant to provide them with an opportunity to provide fine grain detail to the complaint; contacting and taking statements from all available witnesses (including police 
officers); conducting house to house enquiries to identify eye witnesses; securing and reviewing photographic and CCTV images; trawling through incident logs; reviewing radio transmissions of conversations between officers and dispatchers; securing copies of the police officer pocket notebooks (and potentially forensically examining their handwriting); auditing the use of warrant cards to access police stations; reviewing the legality of warrants; and forensically examining an officer's work mobile phone, email account and/ or bank account, did not appear to lead to avoidable delays. In most of the cases sampled, the IO began to review and collect evidence within two weeks of the complaint; complainants were interviewed within three months; and external expert advice (on the use of force, police driving standards and custodial healthcare, amongst others) appeared prompt.

Where delays did occur, they were often unavoidable. Efforts to contact and arrange interviews with witnesses, sometimes numbering in the dozens, took considerable time and frequently ended in disappointment despite numerous attempts to make contact. On occasion, witnesses were on annual leave, sick leave or maternity leave, leading to slight delays before statements could be taken. Moreover, it was not unusual for law firms to ask for an extension to afford sufficient time to meet with accused officers and to have a case conference with counsel. Such delays were typically of less than two to three weeks. While such investigative strands could take months, most investigator actions appeared to be prompt and conducted in earnest.

One major cause for delay, which lay entirely outside of the control of the investigator, occurred when a case became subjudice due to the trial of the complainant. A case which is subjudice means that the matter is under judicial consideration and is therefore prohibited from public disclosure and discussion in other forums (including a disciplinary meeting or hearing). This resulted in a delay of four months before an accused police officer was interviewed in one case.

There were, however, areas in which delays appeared to be entirely avoidable, and within the control of the investigator and the wider policing organisation. Scheduling issues appeared to contribute significantly to protraction. In one case, the officer was informed that it may be 12 months before a date was fixed for the hearing. He was told that 'this is not ideal but due to a backlog, for a number of issues, that is the situation currently' (Progress Report, Case No. 4). The unavailability of panel members and prosecuting counsel led to delays of up to four 
months. Cancellations and the postponement of hearings were not uncommon (Case No. 2 and 3). In a number of cases, the investigation was not progressed due to the IO being on annual leave, usually for a two to three week period. In one case, the case was delayed for three weeks while the IO went on holidays within weeks of commencing the investigation (Case No. 10). In another case, the IO scheduled an interview with the police officer to take place a month and a half later, after his return from annual leave (Case No. 1). Delays also occurred when an investigation was reallocated to a second investigator, who invariably took time to retrace lines of enquiry (Case No. 5).

One particular delay, which appeared to be well within the investigator's control, and which caused significant anxiety for accused officers, was the time it took to interview the accused officer. In many cases, the IO waited until the vast majority of evidence-gathering processes were complete before interviewing the officer concerned, so that the relevant evidence could be put to them. The first interview of suspect police officers took place between three months and eight months of the initial allegation in the majority of cases in the sample. In one particularly stark case (No. 5), it became apparent to the IO to serve notices on two officers 18 months after the allegation was made. Although the investigator was initially focused on officers who had placed a pillowcase over an individual's head, the investigator decided belatedly to focus on the driver and passenger in the cage van who transported the individual to the police station, leaving the pillow case in situ. Quite remarkably, the two accused officers had not previously been interviewed (even as witnesses) as part of the initial investigation. In a separate case, another officer was never interviewed, although she had been under investigation for two years before PSD recommended that her case be dropped (Case No. 6).

By delaying the interview of the officer, the investigator also ran the risk of getting tasked with other jobs:

'[The IO] went to [investigate a major inquiry] but kept hold of our case, so we went to the bottom of his pile..... and it was just drifting and drifting' (Interviewee 3b)

'one of the updates from [the IO] was "I've been busy with another case where an expolice officer has been charged with sex offences basically"' (Interviewee 3b). 
Although there are legitimate reasons for an investigator to gather evidence before conducting an interview with an accused officer, such is the extent of delays, officers observed that it is well known and expected within the policing organisations that misconduct investigations will take an unreasonable amount of time:

'they know if they are going to get a complaint that's it for sort of 2 years......it's always between 18 months and 2 years. People say that's how long a complaint is going to run for......it's never sort of dealt with straight away' (Interviewee 2)

It was clear that such delays and the dysfunctional approach to communication, interviewing and the selection of (potential) breaches during the misconduct process was creating a myriad of mental health problems. Not only was it detrimental to the accused police officer but to the interests of justice. As various panels observed: 'it cannot be in the interests of either the officers concerned or complainants for matters to take so long to come to a hearing' (Regulation 36 Notice, Case No. 5); that 'having the matter hanging over them for years ...together with organisational failings and other matters... the proportionate outcome is to take no further action'; and that proceedings should be withdrawn where 'the eventual hearing itself would be threatened by powerful arguments on delay ...' (Case No. 2).

\section{Conclusion}

The sample of case studies indicate that the police organisation did not fully appreciate the emotional, wellbeing and mental health problems which a misconduct investigation can generate, nor did it have effective safeguards in place to ensure that protraction did not occur. There appeared to be little organisational understanding of the effect that bland notices, vague correspondence and a lack of support could have on an officer's wellbeing and mental health. Feelings of unease, sadness and hopelessness were clearly evident within the sample, which are potential symptoms of depression and anxiety amongst other mental health problems (see Chapter 12 by Bullock and Garland). Yet little was done to address them, or to prevent their manifestation.

There appeared to be a problem of responsibility around the mental health of police officers, particularly those engaged in misconduct processes. The interviews and the associated internal documents indicated a remarkable lack of dialogue and mutual understanding between police officers and their senior officers, and between police officers and the officials 
who were investigating them. The police organisation did not appear to have measures in place to address the positive and negative risks of harm associated with the misconduct process, and how these harms manifested themselves if and when an officer returned to work. Positive risks, in this sense, refers to acts that the officer may do which are potentially damaging, such as a loss of control, aggressive acts, irrational decision-making and disproportionate use of force (Rostow and Davis, 2004; Miller, 2015). Negative risks, on the other hand, connote what the officer may neglect to do, such as dereliction of duty, insubordination and rejection of supervision and accountability. Rather than preventing and addressing these risks, police misconduct appears to be highly stigmatised, leading to the reinforcement of negative stereotypes and the organisation-wide avoidance of responsibility for the mental health and wellbeing of accused police officers.

It is clear that the misconduct process permanently affected the opinions and behaviours of accused police officers. Yet, the police force under review appeared to largely ignore the impaired opinions and behaviours conveyed by the interviewees. This research has shown that police officers who go through a protracted misconduct process could arguably be considered to be vulnerable due to the stresses and behavioural changes involved. Trigger points, such as the birth of a child during a misconduct investigation can be an amplifier of mental health problems, yet they are not being routinely picked up by investigators and supervisors. Instead of providing assistance and alleviating potential mental health problems and their triggers, investigators appeared to be overzealous, oppressive even, in their pursuit of a successful outcome. It is clear that a successful outcome to an investigating officer meant a finding of 'proven', rather than a successful outcome from a mental health perspective. Confirmation bias appeared to loom much larger than any real concern for police officer wellbeing.

For the accused police officer, potentially (and permanently) changed and chronically embittered through their experience of the misconduct process, future efforts to avoid the use of force, turning a blind eye to minor crimes and/ or failing to report issues of misconduct by others (due to their distrust of the various structures and processes) may ultimately amount to misconduct. Through inaction and the prioritisation of self-preservation strategies over public service, as a consequence of their experiences in the misconduct process, such police officers may represent a threat to public safety. Despite an increased focus on risk management within policing organisations, the absence of effective structures and processes which could 
prevent and address mental health problems, mitigating the possible occurrence of subsequent misconduct or liability for future police malpractice, was stark. Instead, the structures and processes for police misconduct appeared to directly threaten the mental health, welfare and behaviours of police officers, potentially risking public safety, without any real checks and balances.

More generally, the problem appeared to lie predominantly with the police organisation, rather than the individual officer. Misconduct investigators and managers did not appear to understand the social milieu of the culture within which they work, amplifying rather than mitigating mental health problems. This is startling considering the fact that it is relatively well established, at least within the academic literature, that '.. the stressors ranking most highly within police work are not specific to the occupation, but to organizational issues such as the demands of work impinging upon home life, [and the] lack of consultation and communication' (Bullock and Garland, Chapter 12). Bullock and Garland point to recent research which suggests that a sizeable majority of police officers have experienced feelings of stress, anxiety and other mental health issues, which have been directly caused or made worse by the police organisation. They note that the organisational nature of these stressors act as a major amplifying factor since the officer has no control and so cannot easily confront nor rectify the problem.

A number of new policies and processes have reportedly been introduced by the police service under review since 2017 (the last case of exoneration examined). These include the employment of new occupational health therapists, the appointment of a wellbeing lead, the introduction of new processes to monitor the duration of misconduct investigations, and more established links with external support agencies, such as Mind (formerly the National Association for Mental Health) and Oscar Kilo (an online portal of mental health resources established as part of the national police wellbeing service). It is likely that these will result in improved outcomes for officers who go through the disciplinary process, but examining whether and to what extent they ultimately affect change requires further study. With an eye to the recent past, integrity checks, fitness-for-duty evaluations and Employee Assistance Programmes (EAPs) have been adopted by police forces in England and Wales in recent years, yet it remains unclear whether and to what extent they are being utilised systematically within misconduct processes. None of the interviewees spoke of such programmes and their use was not addressed in the force's own internal documents concerning the officers' cases. 
With reference to the typology used by Bullock and Garland in Chapter 12, many of the recent changes appear to amount predominantly to secondary interventions (the employment of more occupational health therapists) and tertiary interventions (the provision of external psychological counselling), rather than primary interventions (the removal or reduction of stressors at their source, i.e. their organisational causes). Although psychological sciences have been utilised for decades, applied foremost in the intellectual and psychometric testing of new recruits (Terman et al, 1917), basic findings do not seem to be embedded or applied with sufficient seriousness within policing organisations.

Lastly, there is some evidence to suggest that the recent and widespread introduction of Body Worn Cameras (BWC) is helping to alleviate the stress readily associated with misconduct investigations, as interviewees intimated:

'When I came back out we were all given cameras......we all got body worn cameras which you can view after the incident and write your statements from. So that, at the time, would have helped and just made me feel more comfortable when I got back out as to what I was doing and how it was going to be presented ...' (Interviewee 1).

'We like cameras ...it has knocked so much out of the park like ... claims of police brutality or not doing your job...' (Interviewee 5).

However, video footage is open to interpretation, as seen in the case of the vehicle collision (see also Ariel et al, 2016). Without appropriate checks and balances in place, a zealous investigator may still be able to persist with a (very) weak case unchallenged.

The residual result is that there is a real need for police services to embrace best practice in a mental health context across every facet of the police organisation, not least within misconduct processes. This pilot study indicated that the misconduct process within one of the largest police services in England and Wales is largely devoid of meaningful mental health support, potentially contributing to, rather than addressing, mental health problems. Potential issues of anxiety, stress, PTSD, chronic embitterment and post-traumatic embitterment disorder (PTED), among others, were left almost entirely unaddressed by the policing organisation. 


\section{$\underline{\text { References }}$}

Ariel, B. et al. (2016). Wearing body cameras increases assaults against officers and does not reduce police use of force: Results from a global multi-site experiment. European Journal of Criminology, 13(6), 744-755.

Bayliss, A. and Quinton, P. (2013). Risk, bureaucracy and missing persons: An evaluation of a new approach to the initial police response. London: College of Policing

Blagden, N. (2012). Policing and Psychology. London: Sage.

Brewer, N. and Wilson, C. (eds.) (1995). Psychology and Policing. London: Taylor and Francis, Psychology Press.

Bullock, K. and Garland, J. (2019). The organisation doesn't particularly consider itself responsible for you': organisational support for officers injured in the line of duty and organisational (in)justice. Policing and Society, DOI: 10.1080/10439463.2019.1606807.

College of Policing (2017). Guidance on outcomes in police misconduct proceedings. Available at: https://www.app.college.police.uk/wp-content/uploads/2017/10/MIsconductC621I0617_Guidance-on-outcomes-in-police-misconduct-proceedings_12.10.17.pdf

(Accessed: 1 June 2018).

Fyfe, N., Stevenson O. and Woolnough, P. (2015). Missing persons: the processes and challenges of police investigation. Policing and Society, 25(4), 409-425.

Gershon, R., Barocas, B., Canton, A., Li, X. and Vlahov, D. (2009). Mental, Physical, and Behavioral Outcomes Associated with Perceived Work Stress in Police Officers. Criminal Justice and Behavior, 36 (3): 275-289.

Glaser, B. (1992). Basics of Grounded Theory Analysis. CA: Sociology Press.

Glaser, B. and Strauss, A. (1967). The Discovery of Grounded Theory: Strategies for Qualitative Research. TX: Transaction.

Hickman, M.J., Fricas, J., Strom, K.J. and Pope, M.W. (2011). Mapping Police Stress. Police Quarterly, 14(3): 227-250.

Independent Office for Police Conduct (IOPC) (2019). Police Complaints Information Bulletin. Available at:

https://www.policeconduct.gov.uk/sites/default/files/Documents/statistics/quarterly/Q31819/ West_Midlands_Q3_1819.pdf (Accessed: 1 March 2019).

Kitaeff, J. (ed.) (2011). Handbook of Police Psychology. London: Routledge 
Linden, M., Baumann, K., Rotter, M. and Schippan B. (2008). Diagnostic Criteria and the Standardized Diagnostic Interview for Posttraumatic Embitterment Disorder (PTED). International Journal of Psychiatry in Clinical Practice, 12(2), 93-96

McCreary, D.R., Fong, I., and Groll, D.L. (2017). Measuring Policing Stress Meaningfully: Establishing Norms and Cut-Off Values for the Operational and Organizational Police Stress Questionnaires. Police Practice and Research 18(6): 612-623.

Meffert, S.M., Metzler, T.J., Henn-Haase, C., McCaslin, S., Inslicht, S., Chemtob, C., Neylan, T. and Marmar, C.R. (2008). A Prospective Study of Trait Anger and PTSD Symptoms in Police'. Journal of Traumatic Stress, 21(4), 410-416

Miller, L. (2015). Why cops kill: The psychology of police deadly force encounters. Aggression and Violent Behaviour, 22, 97-111

Ministry of Justice (2018). Criminal Court Statistics Quarterly, England and Wales, January to March $2018 . \quad$ Available at: https://assets.publishing.service.gov.uk/government/uploads/system/uploads/attachment_data /file/720026/ccsq-bulletin-jan-mar-2018.pdf (Accessed: 1 May 2019).

Monckton-Smith, J., Adams, T., Hart, A.G., and Webb, J. (2013). Introducing Forensic and Criminal Investigation. London: Sage.

Morash, M., Dae-Hoon K. and Haarr, R. (2006). Gender Differences in the Predictors of Police Stress. Policing: an International Journal of Police Strategies and Management, 29(3): 541-563.

Noblet, A., Rodwell, J. and Allisey, A. (2009). Police Stress: the Role of Psychological Contract and Perceptions of Fairness. Policing: an International Journal of Police Strategies and Management, 32 (4): 613-630.

Open Justice (2015). The truth about criminal cases. Available at: http://open.justice.gov.uk/courts/criminal-cases/ (Accessed: 1 December 2017).

Punch, M. (2009). Police Corruption: Deviance, Accountability and Reform in Policing. London: Routledge.

Reiner, R. (2010). The Politics of the Police. Oxford: OUP.

Roach, J. and Pease, K. (2013). Police overestimation of criminal career homogeneity. Journal of Investigative Psychology and Offender Profiling, 11( 2), 164-178

Rossmo, D.K. (ed.) (2009). Criminal Investigative Failures. Baton Rouge: CRC Press.

Rostow, C.D. and Davis R.D. (2004). A Handbook for Psychological Fitness-for-Duty Evaluations in Law Enforcement. New York: Psychology Press. 
Schaible, L.M. and Six, M. (2015). Emotional Strategies of Police and their Varying Consequences for Burnout. Police Quarterly. 19(1): 3-31.

Slate, R.N., Wesley Johnson, W. and Colbert, S.S. (2007). Police Stress: A Structural Model. Journal of Police and Criminal Psychology, 22 (2): 102-112.

Terman, L.M., Otis, A.S., Dickson, V., Hubbard, O.S., Norton, J.K., Howard, L., Flanders, J.K. and Cassingham, C.C. (1917). A trial of mental and pedagogical tests in a civil service examination for policemen and firemen. Journal of Applied Psychology, 1(1), 17-29.

Waddington, P.A.J. (1998). Policing Citizens. London: Routledge. 